\title{
Investigations of color center phenomena in Topaz and Quartz through electron spin resonance with reference to optical absorption and nuclear magnetic resonance: Implications for extended mineral applications
}

\author{
Darius Greenidge \\ Shizuoka University Office for International Collaboration / Office for the Promotion of Global Education Programs, 836 Ohya Suruga-ku Shizuoka \\ City 422-8529, Japan
}

*Corresponding author: greenidge.darius.c@shizuoka.ac.jp

\section{Article history}

Submitted 20 December 2017

Revised 19 March 2018

Accepted 1 April 2018

Published Online 30 April 2018

\section{Graphical abstract}

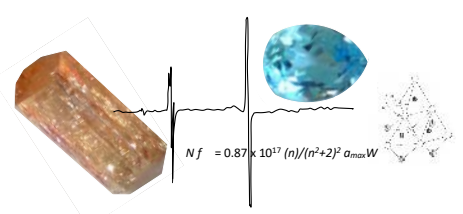

\begin{abstract}
Optical absorption, electron spin resonance (ESR) and nuclear (NMR) studies of silicate minerals such as quartz and topaz help to reveal the nature of a variety of colors which are derived from defects within the crystal structures involving the presence of impurities, trapped holes, and electrons. The present study was inspired by color changes in cinnabar, which upon exposure to sunlight, turns from vermillion red to black under certain conditions, the solid state physical reasons for which have not yet been described. Smoky and amethyst quartz are also bleached by energy from the Sun; reactions that can be reversed by the process of artificial irradiation and heat treatment. Topaz, the focus of this study, exhibits the imperial yellow variety from Ouro Preto, Brazil, which bleaches upon exposure to high temperatures and gives rise to a pink color if chromium is present as an impurity. For the blue variety of topaz, which arises from the irradiation of colorless topaz to smoky, then heat treating to blue, the crystal chemistry remains undefined. Many color centers found in topaz are believed to have a relationship to the presence of aluminum in tetrahedral sites, also related to trapped hole/electron defects. Although NMR studies have targeted the presence of ${ }^{27} \mathrm{Al}$ with uncertain results, optical absorption and ESR studies show clear connections to the production of electronic defects related to absorbing centers caused by high energy irradiation. ESR studies indicate that significant information can be attained relative to these defects when the magnetic vector is parallel to the $c$ axis of the crystal. This paper begins to shed light on the responsible mechanisms that may define the crystal chemistry in terms of the electronic environment, with particular emphasis on topaz.
\end{abstract}

Keywords: Color center, electron spin, nuclear spin, optical absorption, topaz

\section{INTRODUCTION}

The challenges to understand and precisely describe the phenomenon of the color change of various minerals is unending but ever fascinating. This work on topaz and quartz was inspired by the sulfide mineral cinnabar and its cubic dimorph metacinnabar $(\mathrm{HgS})$, which are well known in the production of pigments (vermillion) for works of art since antiquity. Upon exposure to sunlight, the red cinnabar may invert to black metacinnabar. The solid-state mechanism for the conversion has not been clarified. Studies of cinnabar derived pigments have been undertaken by numerous scientists and scholars, only to leave the reader with further questions and yet still an unsolved mystery. Particularly, artists have often been the victims of assuming that the crushed cinnabar for their pigments would remain a brilliant red, only for time to have turned the work to black or dark brown after decades of exposure to energy from the sun, such as for the work by Paolo Uccello of the Battle of San Romano. It is the conviction of the author that work on the silicate minerals and glass will lead to the keys that will resolve the true nature of the color transition phenomenon in the poisonous and difficult to work with cinnabar as well as other minerals.
This paper presents in stages, the ongoing study, which takes the opportunity to utilize ESR fortified with optical absorption spectroscopy and nuclear magnetic resonance (NMR) relative to topaz $\mathrm{Al}_{2} \mathrm{SiO}_{4}(\mathrm{OH} / \mathrm{F})_{2}$ and quartz $\left(\mathrm{SiO}_{2}\right)$, for which the knowledge of trapped holes and electron charge transfer has been relatively well established. Interestingly, topaz is of the orthorhombic crystal system when forming at high temperatures and pressures, but may have monoclinic and triclinic sectors for low-temperature environments such as in hydrothermal deposits, as reported by Akizuki et al. (1979). Topaz as well as quartz experience irradiation due to radioactive elements such as uranium and thorium in the surrounding rock, and this gives rise to electronic defects in the crystal structure, and thus the beautiful colors for the gemstones that we have delighted in for centuries. In particular, there is the imperial yellow topaz from Ouro Preto, Brazil, and blue topaz from various localities, often a colorless topaz that is artificially irradiated to a smoky color and then heat treated to blue, the exact reasons for which are not fully understood (Greenidge, 1993). Some impurities are expected to have an influence upon the crystal environment, such as the $\mathrm{Cr}^{3+}$ impurity in topaz responsible for the pink color. Interestingly, this color does not appear visible to the eye until yellow topaz which contains $\mathrm{Cr}$ experiences subsequent heating. 
It just so happens that topaz of hydrothermal (low-grade origin) is found to contain more chemical impurities and hydroxyl than the variety of the higher grade, although the hydroxyl is stoichiometric. The higher grade topaz which is orthorhombic is not so easy to change color upon irradiation unless higher energy such as electron beam or neutron irradiation is applied. Thus, for topaz, the higher grade appears to be more stable than the lower grade.

Silicate minerals are quite different from metallic sulfides, but if we focus upon the environment of the outer electrons which are always involved in color phenomena, we shall have a universal stage with which to build a frame of reference. The necessity for the pursuit of knowledge through optical absorption, ESR and NMR are presented. In the quest to fully understand the electronic environment of these minerals, support information derived from visible absorption spectra is also provided through the exploration of a variety of topaz crystals, with some being rotated through the magnetic field of the ESR spectrometer. As the study progresses, the full details of the electronic processes are expected to be revealed from the combination of these experimental results and applied to the exploration of the phenomenon in cinnabar and metacinnabar.

\section{EXPERIMENTAL}

\section{Materials}

Primary materials used in this research are topaz crystals from various parts of the world, but mainly from Brazil. The colors range from, yellow, pink, blue, and brown and some are colorless. Quartz is the smoky variety which is common worldwide, with the best varieties coming from Scotland and Arkansas of the United States.

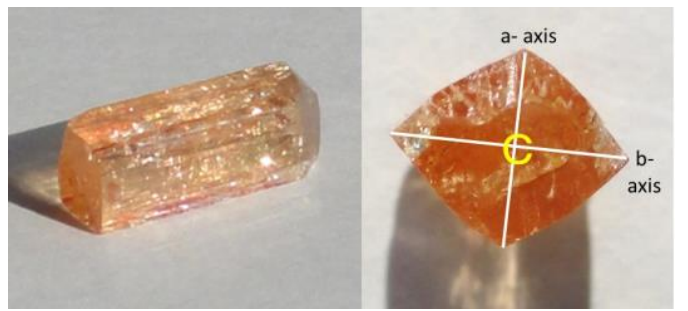

Fig. 1 Photo of an imperial yellow topaz from Ouro, Preto Brazil, Left: showing prism faces that are striated (long, $\mathrm{C}$ axis of the crystal which is horizontal) due to twinning and internal fractures that are likely resulting from the high water pressure canon used to remove the crystals from the clay matrix that results from extreme weathering of feldspar in the original pegmatite (more than 2 billion years in age). Right: Topaz exhibits perfect basal cleavage, as visible looking down the c-axis, which makes the mineral ideal for parallel sample faces that do no need to be cut and polished when applied to optical absorption studies. Other minerals require painstaking polishing in order to avoid the wedge effect which adversely affects the data. The crystal axes defined by $\mathrm{a}$ and $\mathrm{b}$, are also readily apparent, which greatly aids in sample orientation of the crystals for ESR and NMR studies.

\section{Procedure and method}

The procedure for experiments on topaz and quartz graduated from heat treatment, X-ray bombardment and optical absorption to ESR/NMR. Topaz samples were heated in a muffle furnace and for some samples, X-ray bombarded in order to artificially induce the rise of yellow color, simulating the process that occurs in nature due to the presence of nearby radioactive substances. Neutron bombardment of colorless topaz was conducted at the experimental nuclear reactor facility at Kyoto University. Electron spin resonance for topaz was conducted by mounting on a 2-axis goniometer of a JEOL ESR spectrometer at Kanazawa University. NMR data has been previously reported for topaz with use of instruments at Kanazawa University, and further applications shall be applied by Shizuoka University. At this stage we mention the initial survey by ESR for topaz, verifying the presence of significant signals attained from samples that had been untreated by irradiation or artificial heating procedures, particularly for imperial yellow topaz, blue and smoky topaz.
Topaz is normally an orthorhombic mineral, of the space group Pbnm, but it has been found that in the samples from Ouro Preto, Brazil, triclinic $\{\mathrm{hkl}\}$ sectors exist in the core, and monoclinic $\{$ hko $\}$ sectors and orthorhombic sectors in the rim. This appears to be due to the ordering of the hydroxyl ion substituting for the fluorine in hydrothermal topazes, and a detailed study of this phenomenon has been undertaken by Akizuki et al. (1979) and by Phakey and Horney (1976). The triclinic sectors begin to invert to orthorhombic symmetry upon reheating to above $950{ }^{\circ} \mathrm{C}$, however, the mineral then begins to break down to mullite. Whole crystal sizes varied from $1.5 \mathrm{~cm}$ to 4.1 $\mathrm{cm}$ along the $c$ axis, and from $0.5 \mathrm{~cm}$ to $4.5 \mathrm{~cm}$ along the $b$ axis. A 2 $\mathrm{mm}$ diameter region was chosen for each crystal, free of cracks and inclusions, through which the incident light of the spectrophotometer would pass. All samples except for those which exhibited an appropriate thickness and perfect cleavage on (001), were cut perpendicular to the $c$ axis and polished on both sides to attain parallel faces. Some samples such as T-61 were cut parallel to the $c$ axis, such that the absorption spectra with the electric vector vibrating parallel to (010) could be compared with that vibrating parallel to (001). Polarized light was also compared to normal light, the difference in spectra observed being that the peak intensities were lower due to the polarization

Table 1 Topaz samples and their various forms of experimental treatment.

Primary topaz samples/modes of experimental treatment and measurement application

\begin{tabular}{|c|c|c|c|c|c|c|c|c|c|c|}
\hline \multirow[b]{2}{*}{ Sample name } & \multirow[b]{2}{*}{ Local } & \multirow[b]{2}{*}{ Color } & \multicolumn{8}{|c|}{ Type of experimental treatment, measurement application } \\
\hline & & & Heat & $\begin{array}{l}\text { Chem } \\
\text { analyis }\end{array}$ & X-rays & \begin{tabular}{|c|}
$\begin{array}{c}\text { Electron } \\
\text { beam }\end{array}$ \\
\end{tabular} & \begin{tabular}{|c|}
$\begin{array}{c}\text { Neutron } \\
\text { beam }\end{array}$ \\
\end{tabular} & $\begin{array}{c}\text { Optical } \\
\text { absorption }\end{array}$ & ESR & NMR \\
\hline T-51 & $\begin{array}{c}\text { Ouro Preto, } \\
\text { Brazil }\end{array}$ & \begin{tabular}{|c|} 
Yellow/ \\
Pink
\end{tabular} & 0 & & 0 & & & 0 & & \\
\hline 160932 & $\begin{array}{c}\text { Ouro Preto, } \\
\text { Brazil }\end{array}$ & Yellow & & & 0 & & & 0 & & \\
\hline T-62 & $\begin{array}{c}\text { Ouro Preto, } \\
\text { Brazil }\end{array}$ & Yellow & & & & & & 0 & 0 & \\
\hline T-61 & $\begin{array}{c}\text { Ouro Preto, } \\
\text { Brazil }\end{array}$ & Yellow & & & & & & 0 & & \\
\hline 127938 & $\begin{array}{c}\text { Ouro Preto, } \\
\text { Brazil }\end{array}$ & Pink & & 0 & & & & & & \\
\hline 127930 & $\begin{array}{c}\text { Ouro Preto, } \\
\text { Brazil }\end{array}$ & Pink & & & & & & 0 & & \\
\hline T-55 & $\begin{array}{c}\text { Ouro Preto, } \\
\text { Brazil }\end{array}$ & Yellow & 0 & 0 & & & & 0 & & \\
\hline T- 58 & $\begin{array}{c}\text { Katan, } \\
\text { Pakistan } \\
\end{array}$ & Pink & & $\bigcirc$ & & & & & & \\
\hline $\mathrm{T}-1$ & Brazil & Colorless & & & & & & & 0 & 0 \\
\hline $\mathrm{T}-2$ & Brazil & \begin{tabular}{|c|} 
Colorless/ \\
SSmoky
\end{tabular} & & & & & 0 & & 0 & 0 \\
\hline T-54 & Brazil & Colorless & 0 & 0 & 0 & & & 0 & & \\
\hline T-64 & $\begin{array}{c}\text { Colorado, } \\
\text { USA }\end{array}$ & $\begin{array}{c}\text { Colorless/ } \\
\text { Blue }\end{array}$ & 0 & & & 0 & & 0 & 0 & \\
\hline Tres Barres & $\begin{array}{c}\text { Tres Barres, } \\
\text { Mexico }\end{array}$ & \begin{tabular}{|c|} 
Smoky \\
brown
\end{tabular} & 0 & & 0 & & & 0 & & \\
\hline T-60 & Australia & Brown & & 0 & & & & & & \\
\hline
\end{tabular}

Circles $(\bigcirc)$ represent that the sample has undergone treatment and/or measurement.

Some samples have been sliced and applied to multiple modes of treatment and measurement, thus may have two colors listed and additionally named by their mode of treament. Samples with country names only, are from unknown exact locality.

Other samples that were of major use to this work were the following: a blue topaz sample, T-64 (5.45 mm thick), possibly from Colorado, which was initially colorless, irradiated by electron beam to smoky then annealed to blue; three very light pink topaz crystals from Katlang, Pakistan, T-58; a smoky brown topaz from Tres Barres, Brazil, which was also artificially irradiated by X-rays; an Australian brown topaz, T-60; and several small imperial yellow topazes from Ouro Preto, Brazil, which were heat treated to test that all would turn pink above $320^{\circ} \mathrm{C}$. All such samples did turn pink. Both yellow and pink topazes from Ouro Preto were left in direct sunlight for 3 months and more, to test the stability of the colors. There was no observable change. The yellow and pink topazes have been known to be quite stable to sunlight, but some researchers noted that the artificially induced yellow color by irradiation tended to fade not long after exposure to sunlight (Nassau, 1975). Even smoky quartz, after many weeks of exposure to sunlight, begins to fade. However, the smoky in quartz and the yellow color in topaz may be renewed by further irradiation. 
Samples were heat treated in the air on a block of pure fused silica, within a muffle furnace, except for T-54 and T-55, which were heated in a $1200{ }^{\circ} \mathrm{C}$ box furnace. These samples were also heated in air, however, placed in a porcelain crucible. Samples were cooled incrementally, and between each increment, absorption spectra were recorded. Sample T-51, the first of the series, was heated from room temperature to $140{ }^{\circ} \mathrm{C}$, then in 20-degree increments until $200{ }^{\circ} \mathrm{C}$, after which it was heated in 40-degree increments up to $800{ }^{\circ} \mathrm{C}$. At $320{ }^{\circ} \mathrm{C}$, the pink color became visible to the human eye, so the incremental heating was returned to 20-degree increments until $360{ }^{\circ} \mathrm{C}$. The time allowed to reach the target temperature was 1.5 hours, until $200{ }^{\circ} \mathrm{C}$, after which it was given 3.5 hours until after $360{ }^{\circ} \mathrm{C}$, and 4 to 6 hours to reach $800{ }^{\circ} \mathrm{C}$. Once the target temperature was reached, it was maintained for 2 hours in order to be certain to affect as many absorbing centers as possible, and then allowed to cool for over 12 hours. These measures were taken to avoid cracking the crystal due to the high coefficient of expansion for topaz and low thermal conductivity. Studies on the thermal expansion of topaz have been done by Kozu et al. (1929). Samples T-54 and T-55 were heated from room temperature to $150{ }^{\circ} \mathrm{C}$ and thereafter heated in 50-degree increments to $1000^{\circ} \mathrm{C}$. Target temperatures were kept for 2 hours.

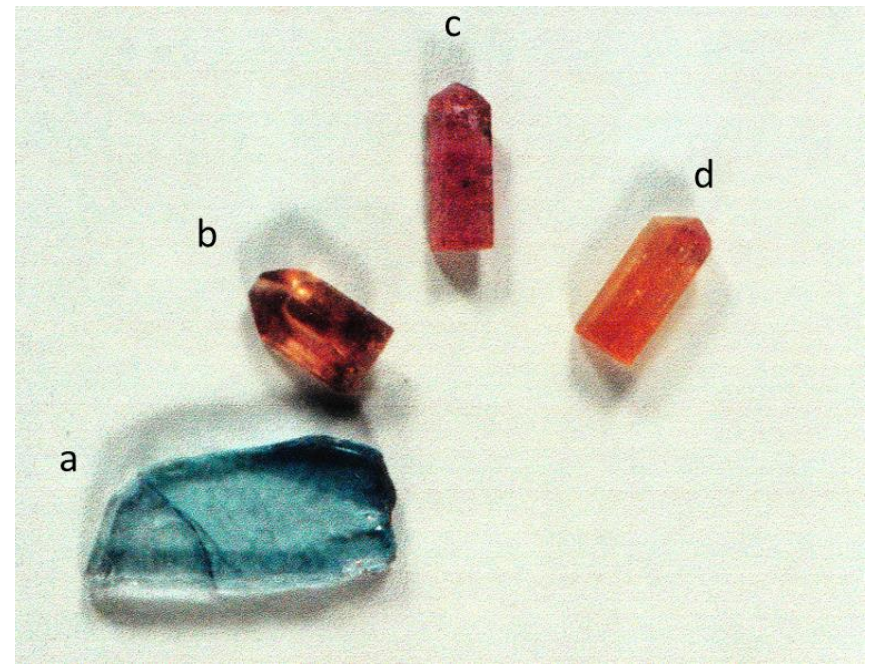

Fig. 2 Topaz samples from which data was taken: a) Blue topaz, sample T-64, which was annealed after irradiation of colorless topaz to smoky. b) Brown topaz from Australia, sample T-60. c) Pink topaz from Ouro Preto (artificially heated to pink), sample 127938. d) Imperia yellow topaz from Ouro Preto, from sample T-55 set.

Instrumentation involves a Cary Model 14 PM Recording Spectrophotometer as the primary optical absorption instrument used in this work. It is designed for automatic absorption spectral recording in the range of $6.19 \mathrm{eV}(2,000 \AA)$ to $0.48 \mathrm{eV}(26,000 \AA)$, i.e., in the ultraviolet, visible and infrared light. The range necessary for the present work is within the visible spectrum. The instrument has good resolving power and high photometric accuracy. A double beam monochromator is employed, consisting of a $30^{\circ}$ fused silica prism, in series with a 600 line/mm echelette grating, each with collimating mirrors and slit system. The detectors are made up of two energy receivers, a 1P28 multiplier phototube for UV and VIS regions, and a lead sulfide cell for the infrared. Light sources are a hydrogen lamp for the UV and a tungsten lamp for the visible and IR regions. Some spectra of the Smithsonian pink sample 127930, were recorded on a Spex 1702 Monochromator, equipped with an HTV R928 photomultiplier tube. The light source was a 50-W halogen lamp.

A Picker Industrial Products D-42215A x-ray machine was used to irradiate the samples set aside for such purpose. A tungsten source was used at maximum $35 \mathrm{kV}$ and $35 \mathrm{~mA}$, the dosage rate in the order of $1.5 \times 10^{6} \mathrm{r} / \mathrm{hr}\left(1.5 \times 10^{4} \mathrm{~Gy} / \mathrm{hr}\right)$ in the air. The very high-energy bombardment was not necessary for the production of the $A_{3}$ band, but electron beam or gamma irradiations are required to produce the blue color in topaz.

Absorption spectra were resolved into pure Gaussian curves by use of a DOS system computer program called "GOOGLY", for Gaussian, Lorentzian or mixed Gaussian/Lorentzian curve resolution. Chemical analyses were performed by ion coupled plasma on a Kyoto Kokensei model UOP-2.

\section{RESULTS AND DISCUSSION}

Partlow and Cohen (1986) have shown radiation-produced "A" optical absorption band color centers to be responsible for color centers in smoky alpha quartz. Nassau and Prescott (1977) and Weeks $(1963,1970)$ have also conducted such studies on smoky quartz. The bands $\mathrm{A}_{1}, \mathrm{~A}_{2}$, and $\mathrm{A}_{3}$ appear at $1.8,2.6$, and $2.9 \mathrm{eV}$, respectively. $\mathrm{A}_{1}$ and $\mathrm{A}_{2}$ bands have also been found in $\mathrm{Na}_{2} \mathrm{OSiO}_{2}$ glass at 1.97 and $2.68 \mathrm{eV}$, respectively (Cohen and Janezic 1983), known in this work as sample CJ83Na20Glass.

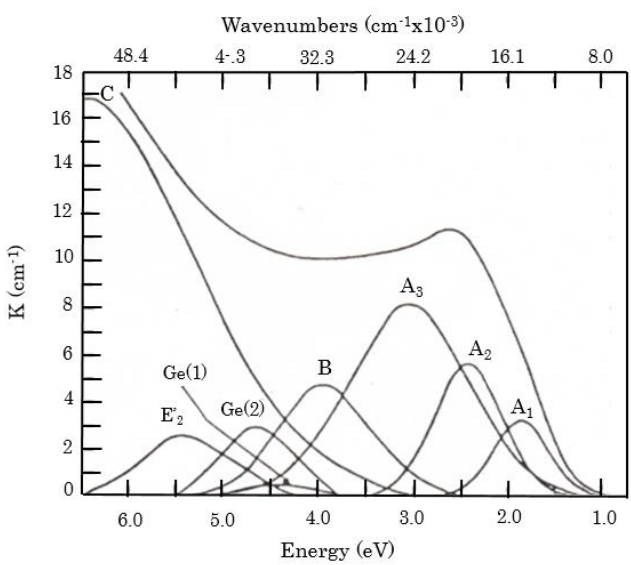

Fig. 3 Resolved optical absorption spectra for smoky quartz (after Partlow and Cohen, 1986). Absorption $\left(\mathrm{K} \mathrm{cm}^{-1}\right)$ is in arbitrary units for all spectra in this article. The B, C, and E centers are defect centers that are trapped electrons in vacancies and unpaired paired electrons. $\mathrm{Ge}(1)$ and $\mathrm{Ge}(2)$ are germanium trapped hole centers, and the A centers are various trapped hole centers which are of major interest regarding topaz.

Quartz is a tectosilicate, having all corners of the tetrahedra shared, except where defects may arise and nonbridging, or dangling bond oxygens may be present. The structure is hexagonal with open channels, which may accommodate interstitial cations. Although the structures of quartz and topaz are different, it is the local structure regarding the silica tetrahedron that is important where defects are concerned. The model for the aluminum-hole defect center (also known as the GOW center, after Griffiths, Owen, and Ward (1954), who first located its electron paramagnetic resonance signal) was theorized by O'Brian (1955), placing the aluminum in a substitutional silicon tetrahedral site. An illustration of the center modified after Griscom (1978) is shown in Fig. 4.

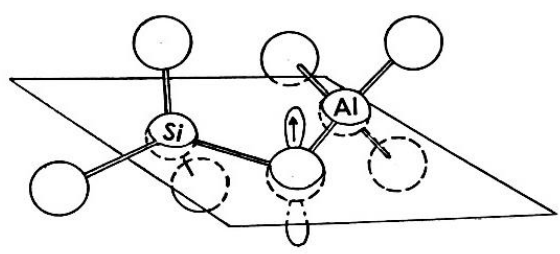

Fig. 4 Aluminum replacing silicon in the tetrahedral site, leaving nonbridging oxygen between two tetrahedrons in quartz (modified after Griscom).

The defect involves a hole on a nonbridging (sometimes referred to as nonbonding) $2 \mathrm{p}$ orbital of an oxygen bridging between substitutional aluminum and a neighboring silicon, with the orbital of the unpaired electron being perpendicular to the plane defined by the 
Si-O-Al bond. Models for smoky quartz show that the $\mathrm{A}_{1}$ band is related to three nonbridging oxygens attached to the aluminum tetrahedron, involving a single trapped hole, the $\mathrm{A}_{2}$ band to two nonbridging oxygens, and the $\mathrm{A}_{3}$ band to only one nonbridging oxygen. All are related to a single trapped hole (Cohen and Makar 1982; Partlow and Cohen 1986), meaning that the hole travels between oxygens in the tetrahedron, but the smoky color may not be produced without the presence of the $\mathrm{A}_{3}$ band.

Aluminum has an ionic radius of 0.47 angstroms in IV coordination, close to that of silicon, which is 0.34 in IV coordination (Whittaker, and Muntus, (1970). The $\mathrm{Al}^{3+}$ substitutional charge deficiency for the $\mathrm{Si}^{4+}$ is compensated for by interstitial ions such as $\mathrm{Li}^{+}, \mathrm{Na}^{+}$, or $\mathrm{H}^{+}$. Upon X-ray irradiation, these ions may leave their sites adjacent to the hole or the electron may be trapped. There has been controversy as to which oxygen, due to chemical inequivalence, serves as the site for the ground state of the aluminum trapped hole center. However, electron double resonance and applied electric fields by Taylor and Farnell (1964) showed that the hole actually hops back and forth between the true equivalent ground state oxygens on each $\mathrm{AlO}_{4}$ tetrahedron. That is, the oxygens are pair-wise equivalent and the hole does not remain on a single oxygen. Schnadt and Schneider (1970) have also shown by electron spin resonance, that there is an excitation of the hole from the ground state pair of oxygens onto the inequivalent pair. This is additional proof that the aluminum is substitutional, and is surrounded by a distorted tetrahedron of four oxygens. That is, the magnitude of the dipole-dipole coupling is apparently reduced due to a lattice relaxation, resulting in an $\mathrm{Al}-\mathrm{O}$ defect separation very much larger than the normal Si-O bond length. This has been calculated to be 2.4 angstroms. The pair-wise equivalent oxygens in the silicon tetrahedra are 1.60 angstroms from the silicon for $\mathrm{O}$ (I) and 1.62 angstroms for $\mathrm{O}$ (II) as noted by Griscom (1978).

Pacchioni et al. (2000) showed by four ab initio cluster calculations for quartz, that the existence of a hole localized in $\left[\mathrm{AlO}_{4}\right]^{\circ}$ (indicating a trapped hole at the aluminum substituted for silicon tetrahedral site) does exist, and is consistent with the O'Brien model. In color center studies of imperial yellow topaz, X-ray irradiation produces the yellow color, caused in the same way that smoky color is produced in quartz with the rise of the $\mathrm{A}_{3}$ band, although for quartz, the smoky color is derived from the combination of all three of the A bands, yet not until the appearance of the $A_{3}$. As topaz and quartz do have different structures, the color effects caused by the same local defects in these minerals are different. The X-ray bombardment data showing the increased absorbance of the yellow color in imperial topaz, sample 160932, and the bombardment of colorless topaz sample T-54 are shown in Figs. 5 and 6, respectively.

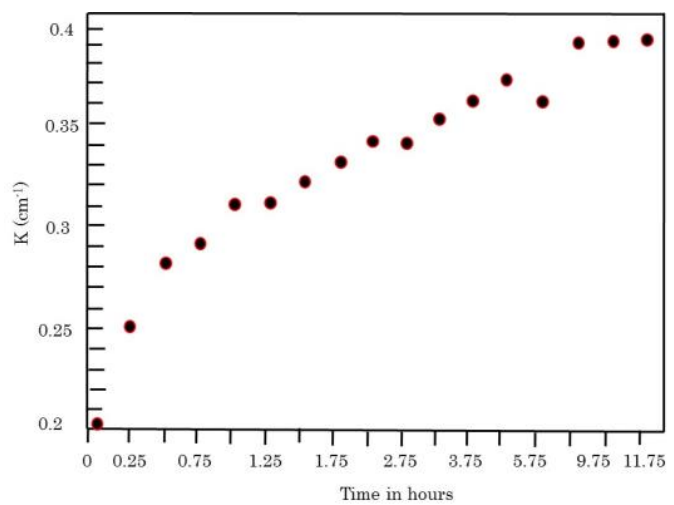

Fig. 5 X-ray bombardment at $35 \mathrm{kV}$ and $35 \mathrm{~mA}$ of imperial yellow sample 160932, saturating after 8 hours. Although weak as compared to the electron beam and neutron bombardment, X-ray irradiation proved to demonstrate the increased absorption due to the likely creation of defect centers, as would occur in nature, where pegmatites contain radioactive elements such uranium.

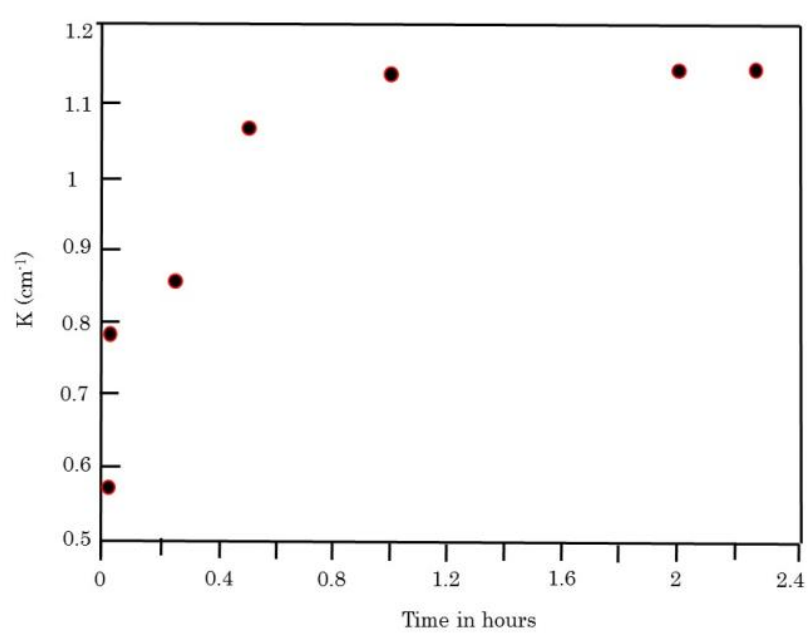

Fig. 6 X-ray bombardment at $35 \mathrm{kV}$ and $35 \mathrm{~mA}$ of colorless sample T54. The sample saturated after only close to 1 hour without a strongly perceptible change in color

All of the measurement points in the above figures represent a restart from 0 hours to the number of hours represented by the $x$-axis. Thus, it is obvious that longer exposure to radiation causes the production of more absorbing centers. The increased depth of the yellow color was strongly perceptible for sample 160932 while only a faint yellow color was barely perceptible for T-54. The reason for this is not clear, but it is believed that colorless T-54 is of higher temperature origin coincident with the original formation of a pegmatite, while 160932 is of secondary origin through hydrothermal activity. The stoichiometrical differences in $\mathrm{OH} / \mathrm{F}$ content may account for the difference, but further analysis is required. The spectra for the $\mathrm{A}_{3}$ band for imperial yellow sample $\mathrm{T}-51$, which has been the most useful sample of this work, is shown in Fig. 7.

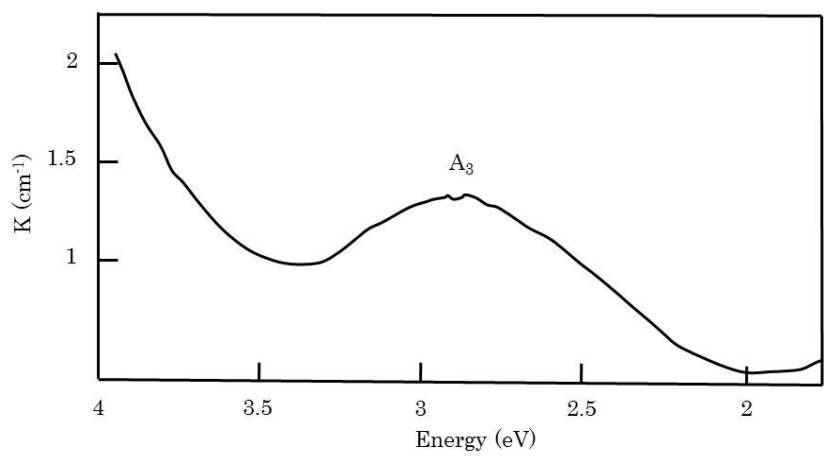

Fig. 7 The optical absorption spectrum for imperial yellow topaz, sample T-51, before any heat or irradiation treatments.

Data retrieved from optical absorption spectra experiments are shown in Table 2. It is hoped that this information will be useful in the comparison of all-optical absorption spectra in minerals. Table 3 is data for bleaching temperatures of selected samples.

Table 2 Optical absorption bands in quartz, topaz and glass, with values for locations of peaks, widths at half maximum in electron volts $(\mathrm{eV})$.

\begin{tabular}{|c|c|c|c|c|c|c|}
\hline \multicolumn{7}{|c|}{ Comparative quartz, topaz, glass sample absorption spectral data } \\
\hline \multirow{2}{*}{ Sample } & \multicolumn{6}{|c|}{ Band Peak eV and Width $1 / 2 \max$ (in parentheses) $\mathrm{eV}$} \\
\hline & $\mathrm{A}_{1}$ & $\mathrm{~A}_{2}$ & $\mathrm{~A}_{3}$ & B & $\mathrm{Cr} \# 1$ & $\mathrm{Cr} \mathrm{H}_{2}$ \\
\hline Smoky quartz & $1.81 \sim 1.88(0.60 \sim 0.71)$ & $2.40 \sim 2.60(0.81-0.87)$ & $2.93 \sim 3.06(1.40 \sim 1.55)$ & $3.92 \sim 3.97(1.15 \sim 1.30)$ & & \\
\hline CJ83 $\mathrm{Na2} \mathrm{O}$ Glass & $1.97(0.50)$ & $2.68-2.70(0.95)$ & & $4.04(1.16)$ & $\tau$ & \\
\hline Yellow topaz T-51 & 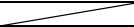 & $\underline{\omega}$ & $2.93 \sim 3.06(1.40 \sim 1.55)$ & $3.92 \sim 3.98(1.20 \sim 1.50)$ & $2.36(0.56)$ & $3.11(0.60)$ \\
\hline Blue topaz T-54 & $1.98(0.41)$ & 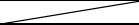 & 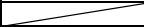 & _ & 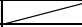 & \\
\hline $\begin{array}{l}\text { Smoky brown topaz } \\
\text { Tres Barres }\end{array}$ & & $2.47(0.89)$ & & $3.65(1.20)$ & & \\
\hline
\end{tabular}

CJ83 Na2O Glass represents the sample from Cohen and Janeic 1983

Slashes across cells indicate "not found" 
Table 3 Selected sample bleaching temperatures. Although many samples were tested for bleaching, only the most representative are mentioned here.

\begin{tabular}{|c|c|c|c|c|c|c|}
\hline \multirow{2}{*}{ Sample type } & \multicolumn{6}{|c|}{ Band Peak heat bleaching temperatures, degrees C } \\
\hline & $\mathrm{A}_{1}$ & $\mathrm{~A}_{2}$ & $\mathrm{~A}_{3}$ & B & $\mathrm{Cr} \# 1$ & $\mathrm{Cr} \# 2$ \\
\hline Smoky quartz & 280 & 280 & $320 \sim 460$ & 280 & 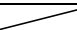 & 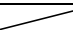 \\
\hline CJ83 Na2O Glass & 177 & 177 & & $x$ & 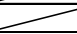 & 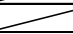 \\
\hline Yellow topaz T-51 & 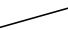 & 1 & $320 \sim 480$ & $\mathrm{x}$ & $\mathrm{x}$ & $\mathrm{x}$ \\
\hline Blue topaz T-64 & 230 & 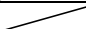 & & Z & & \\
\hline $\begin{array}{c}\text { Smoky brown topaz } \\
\text { Tres Barres }\end{array}$ & & $\sim 320$ & & 320 & & \\
\hline
\end{tabular}

$\mathrm{x}=$ Did not bleach upon heating

slashes $=$ Not applicable

Topaz is a nesosilicate and it contains isolated silica tetrahedra, which are attached to octahedrally coordinated $\mathrm{Al}$ bonded oxygens. The composition of topaz is $\mathrm{Al}: 29.61 \%\left(55.95 \% \mathrm{Al}_{2} \mathrm{O}_{3}\right)$, Si: $15.41 \%$ (32.97\% $\mathrm{SiO}_{2}$ ), $\mathrm{H}: 0.50 \%\left(4.45 \% \mathrm{H}_{2} \mathrm{O}\right), \mathrm{O}: 43.02 \%$, and $\mathrm{F}: 11.47 \%$. The empirical formula is $\mathrm{Al}_{2}\left(\mathrm{SiO}_{4}\right) \mathrm{F}_{1.1}(\mathrm{OH})_{0.9}$ (Anthony 1997). With aluminum in topaz present in stoichiometric amounts, it is expected that it may replace $\mathrm{Si}$ in tetrahedral sites, as it does in sillimanite, $\mathrm{Al}_{2} \mathrm{SiO}_{5}$ (by up to $50 \%$ ). Aluminum is also replaced by various ions such as iron or chromium, in its usual octahedral site. The excess or deficiency of aluminum is not an indication of its site occupancy, but it has been shown for quartz that higher concentrations of $\mathrm{Al}$ in certain portions of the crystal appear to give rise to deeper colors (Nassau 1974). However, the depth of color may be more relative to the degree of saturation reached by irradiation. In this respect, observations of optical absorption bands may give an indication of related color center defects in various minerals.

The pink color produced by heat treatment of the Ouro Preto samples appears to be due to chromium located in the aluminum octahedral sites. On heating to above $320{ }^{\circ} \mathrm{C}$, the yellow color disappears. Above $1000{ }^{\circ} \mathrm{C}$, the topaz begins to break down to mullite, an anhydrous alumino-silicate. The absorption band due to the $\mathrm{Cr}^{3+}$ is located at $2.36 \mathrm{eV}$. Chromium needs to be present in as little as 100 $\mathrm{ppm}$ to have a visible effect, and the production of the color may be detected after heating to $320{ }^{\circ} \mathrm{C} . \mathrm{Cr}^{3+}$ in mullite studies by Ikeda et al. (1992) showed the same optical absorption bands. $\mathrm{The}^{\mathrm{Cr}^{3+}}$ bands have also been found in albite glass studied by Keppler (1992), which may show a relationship to the defects present in topaz. ICP chemical analysis data for chromium concentrations in topaz samples of this work are listed in Table 4. It is noteworthy that the topaz of the richest pink color from Ouro Preto, contained $660 \mathrm{ppm}$ of $\mathrm{Cr}$, and the lightest shaded pink sample from Pakistan contained $130 \mathrm{ppm}$. Pink topaz from Ouro Preto, Brazil, with the highest $\mathrm{Cr}$ content in this sample selection, is well known to have the most impressive depth of color prized for gemstones.

Table 4 Impurity metal content for various topaz samples (ppm). The metals targeted in these analyses are those for which the colors observed are commonly thought responsible.

\begin{tabular}{|c|c|c|c|c|}
\hline \multirow{2}{*}{ Sample } & \multirow{2}{*}{$\begin{array}{c}\text { Local/ } \\
\text { Color }\end{array}$} & \multicolumn{3}{|c|}{ Impurity metal content } \\
\cline { 3 - 5 } T-55 & $\begin{array}{c}\text { Ouro Preto, } \\
\text { Brazil/yellow }\end{array}$ & 110 & Fe & $\mathrm{Ti}$ \\
\hline $\mathrm{T}-54$ & $\begin{array}{c}\text { Brazil/ } \\
\text { colorless }\end{array}$ & 0 & 75 & 14 \\
\hline T-60 & $\begin{array}{c}\text { Australia/ } \\
\text { brown }\end{array}$ & 0 & 330 & 110 \\
\hline T-58 & $\begin{array}{c}\text { Katlan, } \\
\text { Pakistan/ pink }\end{array}$ & 130 & 55 & 0 \\
\hline 127938 & $\begin{array}{c}\text { Ouro Preto, } \\
\text { Brazi// } \\
\text { pink }\end{array}$ & 660 & 35 & 0 \\
\hline
\end{tabular}

Dickenson and Moore (1966) indicated that there is evidence of $\mathrm{Cr}^{3+}$ in yellow topaz in their ESR studies, however, its presence in high concentration in optical absorption studies is observed by 320
${ }^{\circ} \mathrm{C}$, and strongly evident by $760{ }^{\circ} \mathrm{C}$. A tinge of pink color was also visible to the human eye after the sample was cooled to $320^{\circ} \mathrm{C}$. It has been noted by da Costa et al. (2000) that a pink color appears by 600 ${ }^{\circ} \mathrm{C}$, but none of the samples tested in this work showed such a late appearance of the pink color. Taran et al. (1994) also observed a doublet chromium peak in this position. They described the temperature effects of chromium in topaz as being very small, however, it was not noted as to whether or not they had experimented with imperial topaz before the color change from yellow to pink. This work indicates a notable change in absorbance with heat treatment for the chromium band in topaz. It is believed that there may still be some remnant of the $\mathrm{A}_{3}$ peak left under the chromium peak at $3.1 \mathrm{eV}$, but too small to be resolvable. The absorption spectrum for sample T-51 after heat treatment is shown in Fig. 8.

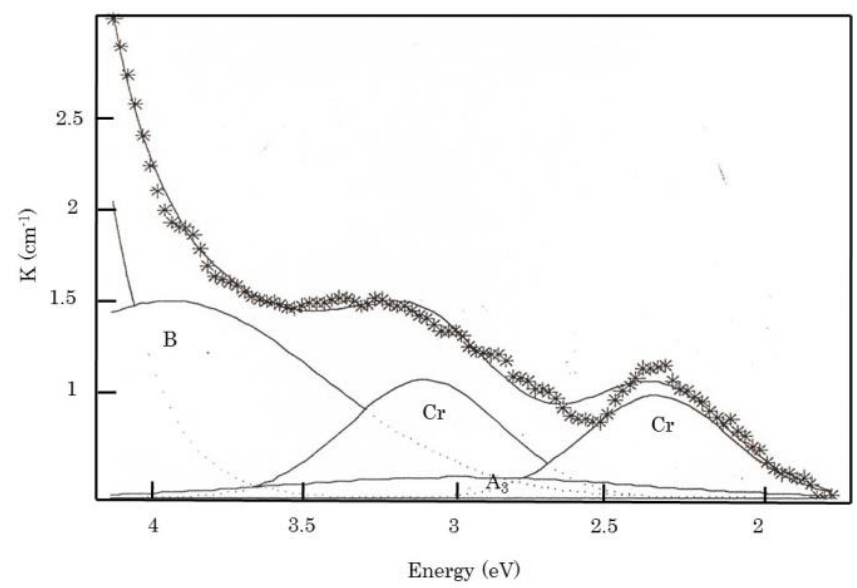

Fig. 8 The optical absorption spectrum for imperial yellow topaz, sample T-51, after heating to above $800{ }^{\circ} \mathrm{C}$. The $A_{3}$ band is bleached until it is almost unrecognizable, and the rise of two chromium bands $(\mathrm{Cr})$ is prominent. The asterisk curve represents the original spectrum before smoothing and resolving.

It is well known that transition metal ions are responsible for colors in many minerals. One of the most famous is that of $\mathrm{Cr}^{3+}$ in the ruby variety of corundum, $\mathrm{Al}_{2} \mathrm{O}_{3}$ (Nassau 1983). $\mathrm{The}^{\mathrm{Cr}^{3+}}$ occupies a distorted octahedral site in the corundum hexagonal structure as an impurity ion replacing aluminum. Similarly, chromium is replacing aluminum in the octahedral sites of the topaz structure. The color caused by such substitution in these minerals is considered to be due to crystal field effects. That is to say, the central metal ion is subjected to an electric field due to atoms immediately surrounding it. The crystalline field distorts the spherical symmetry of the free atoms (Burns 1970; Marfunin 1979). When surrounded by an octahedral field, the $3 \mathrm{~d}$ levels no longer maintain the same energy and there is a crystal field splitting, the size of such splitting dependent upon the magnitude of the field. As white light passes through the ruby crystal, $2.2 \mathrm{eV}$ energy causes excitation from the ${ }^{4} \mathrm{~A}_{2}$ to the ${ }^{4} \mathrm{~T}_{2}$ level, causing absorption of the yellow-green part of the spectrum, while $3.0 \mathrm{eV}$ energy excites to the ${ }^{4} \mathrm{~T}_{1}$ level, causing absorption in the violet part of the spectrum. Thus, a small blue transmission of light plus the strong red transmission gives ruby and pink topaz their color. The reader is referred to the work by Nassau (1983) for further details on this phenomenon in the form of energy diagrams.

Taran et al. (1994) entered into an interesting discussion of transitions for $\mathrm{Cr}^{3+}$ in various minerals including topaz. They explain that all transitions are allowed due to the non-existence of symmetryrelated selection rules and that the least temperature influence is expected for topaz. It is suggested here that more work with respect to the energy transitions relative to the color change in imperial topaz is necessary, and that it may have a relationship to the aluminum trapped hole. Studies on co-precipitated chromia-alumina by Poole and Itzel (1963) and by Poole (1964) displayed these phenomena. Although ordinary white light is enough to excite $\mathrm{Cr}^{3+}$ to electronic states giving rise to the pink color as in ruby corundum, the solid state 
reactions responsible for the color transition in topaz is not yet clear. However, the rise of the pink color does appear to be coincident with the thermal bleaching of the yellow in the samples studied.

The oscillator strength, $f$, was calculated from the modified Smakula equation of Lax (1955) and Dexter (1956):

$$
N f=0.87 \times 10^{17}(n) /\left(n^{2}+2\right)^{2} a_{\max } W
$$

where $N$ is the number of absorbing centers, $n$ the refractive index (1.64 for topaz), $a_{\max }$ the maximum absorbance, and $W$ the width at one half maximum. A value calculated for chromium in topaz on the order of $10^{-5}$ (actually $7.4 \times 10^{-5}$ ) attributes the color of chromium to crystal field effects.

The Fe content in the T- 60 brown topaz is quite high and expected to be present in interstitial sites as it often does for quartz, although tetrahedral site replacement is possible. The spectrum of brown topaz such as Tres Barres, interestingly indicates the presence of the B and $\mathrm{A}_{2}$ bands after bombardment, while the spectrum for blue topaz T-64 which was bombarded by the electron beam and then annealed, exhibits primarily the presence of the $\mathrm{A}_{1}$ band. No significant amounts of impurity elements are believed to contribute to this phenomenon in the blue topaz and it is hoped that the candidates for the electronic environment can be defined by further analyses through ESR/NMR.

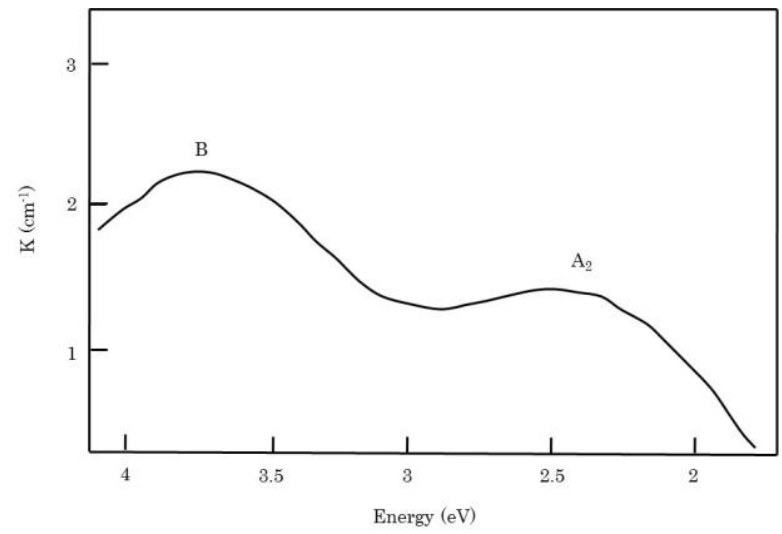

Fig. 9 Smoky brown Tres Barres, Brazil topaz sample spectrum, which was irradiated by $x$-rays. It exhibits the $A_{2}$ and $B$ bands.

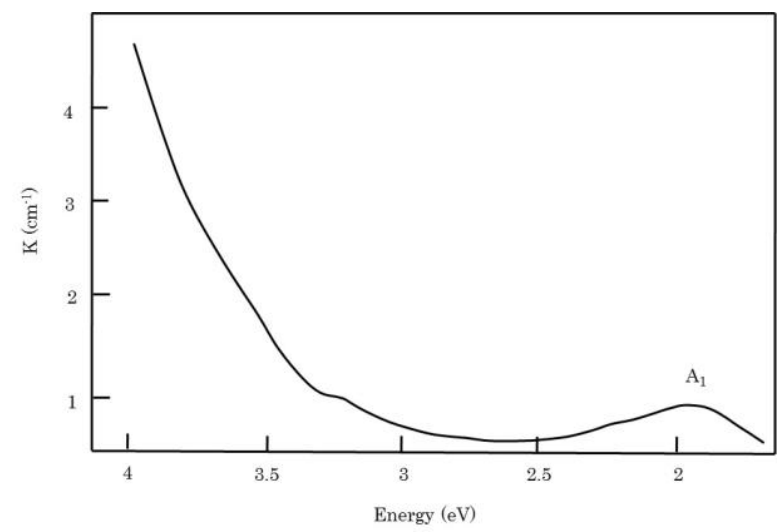

Fig. 10 Blue topaz sample T-64 spectrum, which was irradiated from colorless to smoky, then annealed to blue.

The bombardment of colorless topaz by electron beams is a common practice in the gem industry, however, without detailed scientific knowledge of the mechanisms for the cause of the blue color which arises after annealing, results of the hues that make the gem saleable are haphazard and this culminates in much waste of time and material. Information gained through this research can help to improve that process.

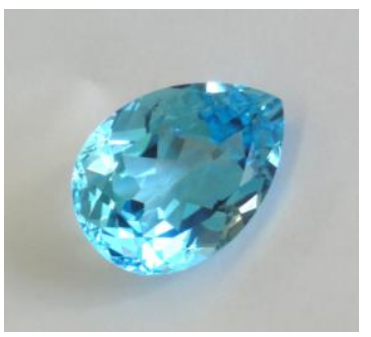

Fig. 11 Blue topaz from Pakistan, which was irradiated from colorless to smoky, then annealed to blue. Some samples deliver hues that are too dark to be desired by the gem industry. The sample depicted here is one that is considered appealing.

A vast number of ESR spectra were produced for topaz samples that were: untreated in any manner, yellow (imperial topaz), colorless, smoky (that which was neutron irradiated), and blue topaz (annealed after irradiation). Selected spectra are given in Figs. 12-14.

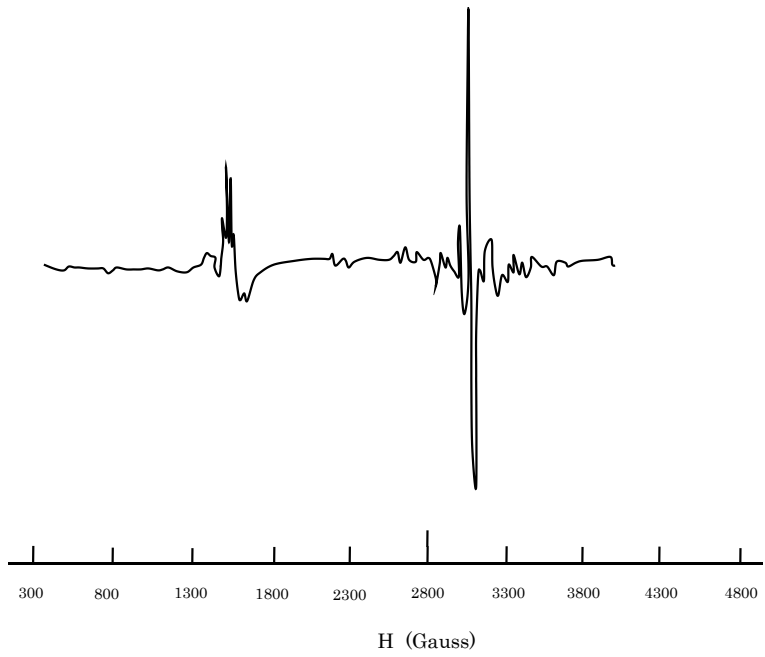

Fig. 12 ESR spectrum for imperial yellow topaz T-62, in the spectral series, which gives unique signals in the region of 3050 to 3300 Gauss. It is expected that this region is directly related to the color centers found in topaz and may correlate well with a comparison to the A bands in optical absorption.

Over the course of 4 to 8 minutes, the crystals were rotated through a magnetic field of $2800+/-2500 \mathrm{G}$, at $9.37 \mathrm{GHz}$ and $5 \mu \mathrm{W}$. While aligning the samples such that one of the 3 crystal axes $(a, b$, $c$ ), remained perpendicular to the magnetic field, rotations through the $a b$ plane, $b c$ plane, $a c$ plane, and sectors between these axes were conducted and significant changes in the spectra recorded in detail. Specifically, those crystals which displayed color phenomenon showed significant changes in spectra in the range of 3050 to $3300 \mathrm{G}$. All crystals showed similar spectra in the range of $1550 \mathrm{G}$, while only the untreated colorless sample showed little variation. This appears to be indicative of defects caused by the effects of radiation, natural or artificial. Further, from the multitude of crystal orientations measured, those oriented with the $\mathrm{c}$ axis parallel to the magnetic field vector appeared to provide the most significant results. Work is being conducted in this area in order to bring a rigorous examination of the hyperfine coupling for these spectra along with the completed measurements and calculations for the crystal structural environment, particularly along the $c$ axis.

NMR studies of aluminum in topaz conducted by Mizuno and Greenidge et al. (2006), showed that there appears to be a relationship between the effects of neutron bombardment of colorless topaz and the placement of ${ }^{27} \mathrm{Al}$ in the octahedral sites, but the sensitivity of the instrument was not adequate enough to detect that for the tetrahedral sites. NMR examination of the samples remains inconclusive when targeting aluminum, which sets the stage for coordinated studies on $\mathrm{Si}$ and impurity elements as well. Studies have been pursued by Xue et al. (2010) in synthesized topaz, where they have been able to verify an 
increased presence of aluminum in the tetrahedral sites and it is likely that further analysis can clarify this for natural samples. Samples T-1 and T-2 have been key samples in this investigation, colorless from the start, but neutron bombarded to smoky for T-2

\section{a}

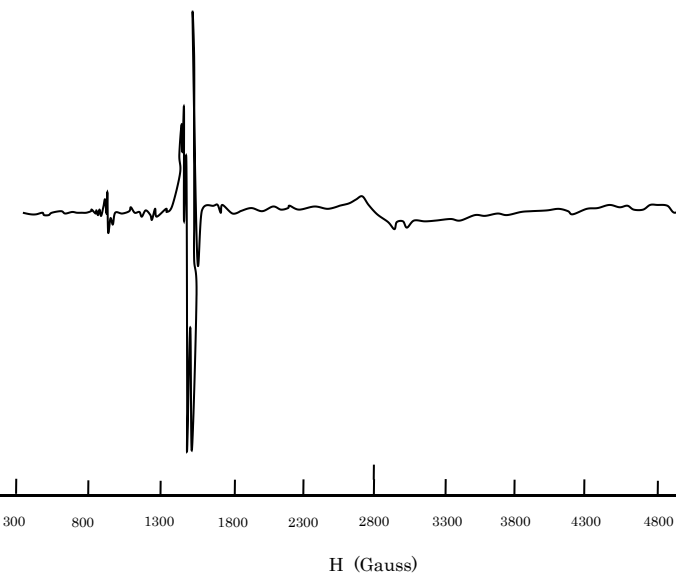

b

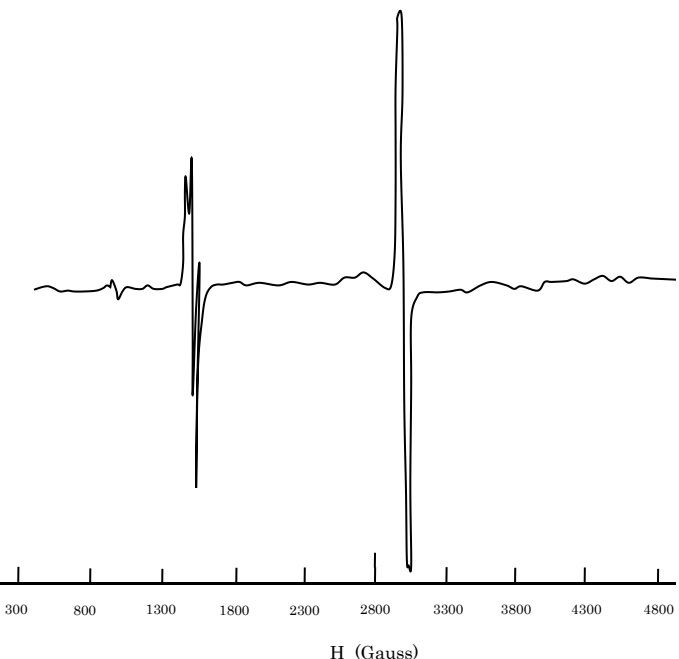

Fig. 13 ESR spectra for colorless topaz T-2 (a) which was bombarded with neutrons and turned smoky, to give the spectra in (b). It is obvious that there is a dramatic change in the region about 3050 to $3300 \mathrm{G}$, which would indicate major damage to the electronic environment of the crystal and proliferation of detectable free radicals. The signal in the region of $1500 \mathrm{G}$ was found to be relatively unchanged in all spectra for topaz and thus considered characteristic for that mineral.
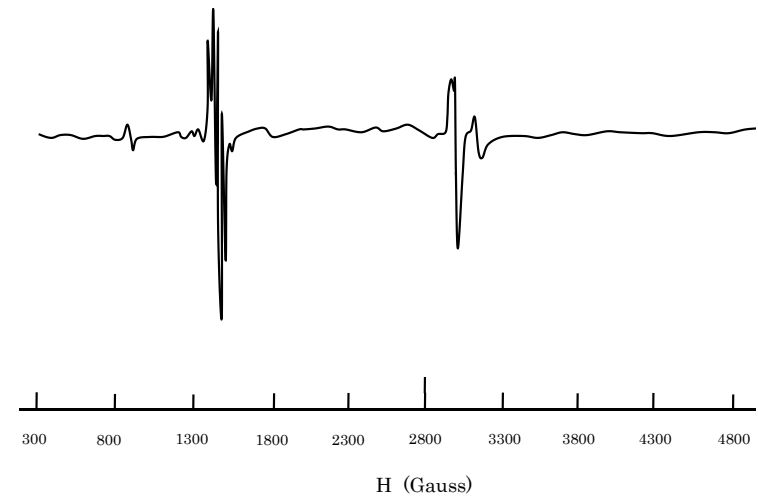

Fig. 14 ESR spectra for blue topaz T-64, in the series with those measured in Figs. 12 and 13. Although the spectra in Fig. 13 from originally colorless sample T-2 are from different crystals than for sample T-64 shown above, it is assumed that the phenomenon is related, as the highest temperature topaz that has been artificially irradiated from the colorless turns smoky and then blue after heating. It is likely that electrons are transferred to centers other than from which they were disturbed, attributing to the change in color.

\section{CONCLUSION}

Studies of optical absorption spectra in topaz interestingly showed the presence of bands similar to those found in smoky quartz, although not simultaneously as in smoky quartz. This is believed to be due to structural differences between the two crystallographic systems and stoichiometric constituents, but artificially induced damage by irradiation produces similar electronic defects that may be related to elemental substitution, particularly with regards to the tetrahedral sites. Work must continue with NMR in the search for aluminum in the tetrahedral sites as well as explore the effects of irradiation on $\mathrm{OH} / \mathrm{F}$ as part of the mineral structure. ESR studies have enhanced our understanding of these phenomena, and the results showed that upon irradiation, there are significant electronic responses that can be detected when the magnetic field is aligned with the $c$ axis of the topaz crystal. Topaz exhibits a crankshaft-like structure of silica tetrahedrons connected to aluminum centered octahedrons when viewed parallel to the $c$ axis. It is as though chains of octahedra are joined by tetrahedra which do not join with one another. The placements of $\mathrm{OH} / \mathrm{F}$ are also concentrated in this direction along the $c$ axis and can play an important role in the crystal environment when affected by irradiation. Further work must be done to fully define the relationship to color centers involving trapped holes and electrons in the crystal structure. The results are also encouraging with respect to pursuing the possibility of similar phenomena in the minerals used as art materials that have inspired this work.

\section{ACKNOWLEDGEMENTS}

Appreciation is expressed for the researchers at Japan's National Institute for Materials Science (formerly, NIRIM: National Institute for Research in Inorganic materials), the Kanazawa University Suhara Laboratory, where Dr. Masahiko Suhara so patiently instructed in the use of ESR, Dr. Andrew Proctor for his development of the curve resolving program, "GOOGLY", and to the late Dr. Alvin J. Cohen for his introduction to the fascinating topic of color centers. Thanks also to Shizuoka University's Hisao Murai and Kenkichi Sakamoto for their offer of the use of ESR instruments, and to the Smithsonian Institution, the section of minerals, for their loan of numerous valuable samples.

\section{REFERENCES}

Akizuki, M., Hampar, M. S., and Zussman, J. (1979). An explanation of anomalous optical properties of topaz. Mineralogical Magazine, 43, 237-241 Anthony, J. W., Bideaux, R. A. (1997). Handbook of Mineralogy: Vol. 2 Silica, Silicates. Tucson, Arizona: Mineral Data Publishing,

Burns, Roger G. (1970). Mineralogical Applications of Crystal Field Theory. London: Cambridge University Press.

Cohen, A. J., Makar, L. N. (1982). Models for color centers in smoky quartz. Physica Status Solidi, (a), 73, 593-596.

Cohen, A. J., Janezic, G. G. (1983). Relationships among trapped hole and trapped electron centers in oxidized soda-silica glasses of high purity. Physica Status Solidi (a), 77, 619-624.

da Costa, G. M., Sabioni, A. C. S., Ferreira, C. M. (2000). Imperial topaz from Ouro Preto, Brazil: Chemical character and thermal behaviour. Journal of Gemmology, 27, 3, 133-138.

Dexter, D. L. (1956). Absorption of light by atoms in solids. Physical Review, series 2, 101, 48-55.

Dickenson, A. C., and Moore, W. J. (1966). Paramagnetic resonance of metal ions in defect centers in topaz. Physical Chemistry of the Solid State, 1953 1966, Bloomington, Indiana: Indiana University Press.

Greenidge, D. C. (1993). Comparison of thermal bleaching of trapped-hole color centers in topaz and quartz, 153p. Doctoral dissertation, University of Pittsburgh, P.A.

Griffiths, J. H. E., Owen, J., Ward, I. M. (1954). Paramagnetic resonance in neutron-irradiated diamond and smoky quartz. Nature, 173, 439-440.

Griscom, D. I. (1978). Defects and impurities in $\alpha$ quartz and fused silica. The Physics of $\mathrm{SiO}_{2}$ and its Interfaces. In Pantelides, S. (Ed.) New York.: Pergamon Press.

Ikeda, K., Schneider, H. (1992). Crystal-field spectroscopic study of Cr-doped 
mullite. American Mineralogist, 77, 251-257.

Keppler H. (1992). Crystal field spectra and geochemistry of tansistion metal ions in silicate melts and glasses. American Mineralogist, 77, 62-75.

Keller, P. C. (1983). The Capão topaz deposit, Ouro Preto, Minas Gerais, Brazil. Gems \& Gemology, 19, 12-20.

Kozu, W., Ueda, J. (1929). Optical and thermal studies of topaz from Naegi, Japan. Science Report, Tohoku University, series 3, vol. 3, 161-170.

Lax, M. (1955). The influence of lattice vibrations on electronic transitions in solids. Photoconductivity Conference, 1954, 111-145, Wiley, New York.

Marfunin, A. S. (1979). Spectroscopy, Luminescence and Radiation Centers in Minerals. New York : Springer-Verlag.

Mizuno, M., Aoki, Y., Endo, K. Greenidge, D. (2006). Local structure analysis of smoky and colorless topaz using single crystal 27Al NMR. Journal of Physics and Chemistry of Solids, 67, 705-709.

Nassau, K., (1974) The effects of gamma rays on the color of beryl, smoky quartz, amethyst and topaz. Lapidary Journal, 4, 20-22,25-26,36-40.

Nassau, Prescott, B. E. (1975). Blue and brown topaz produced by gamma irradiation. American Mineralogist, 60, 705-709.

Nassau. (1975) Smoky, blue, greenish yellow, and other irradiation-related colors in quartz. Mineralogical Magazine, 41, 319, 301-321

Nassau, (1983). The Physics and Chemistry of Color. New York: Wiley.

O'Brien, M. C. M. (1955). The structure of the colour centers in smoky quartz. Royal Society of London Proceedings, 231 A, 404-441.

Oftedal, I. (1963). The germanium contents of some Norwegian topaz specimens. Norsk Geologisk Tidsskrift, 43, 267-269.

Pacchioni, G., Frigoli, F., Ricci, D., Weil, J. A. (2000). Theoretical description of hole localization in a quartz $\mathrm{Al}$ center: The importance of exact electron exchange. Physical Review B, 63, 054102-1-8.
Partlow, D. P., and Cohen, A. J. (1986). Optical studies of biaxial Al-related color centers in smoky quartz. American Mineralogist, 71, 589-598.

Phakey, P. P., Horney, R. B. (1978). On the nature of gown-in defects in topaz. Acta Crystallographica, A 32, 177-182.

Poole, C.P. Jr., and Itzel, J.F. Jr., (1963). Optical reflection spectra of chromiaalumina. Journal of Chemistry and Physics, 39, 12, 3445-3455.

Poole, C. P. Jr. (1964). The optical spectra and color of chromium containing solids. Journal of Physics and Chemistry of Solids, 25, 1169-1182.

Schnadt, R., Schneider, J. (1970). The electronic structure of the trapped hole center in smoky quartz. Physik Der Kondensiterten Materie, 11, 19-42.

Spring M. Grout R. (2002). The blackening of vermilion: An analytical study of the process in paintings. National Gallery Technical Bulletin, 23, 50-61.

Taran, M. N., Langer, K., Platonov, A. N., Indutny, A. N. (1994). Optical absorption Investigation of $\mathrm{Cr}^{3+}$ ion-bearing minerals in the temperature range 77 - 797 K. Physics and Chemistry of Minerals, 21, 360-372.

Taylor, A. L., Farnell, G. W. (1964). Spin lattice interaction experiments on color centers in quartz. Canadian Journal of Physics, 42, 595-607.

Weeks, R. A. (1963). Paramagnetic spectra of $E_{2}^{\prime}$ centers in crystalline quartz. Physical Review, 130, 570-576.

Weeks, R. A. (1970). Paramagnetic resonance and optical absorption in gamma-ray irradiated alpha quartz: The Al-center. Journal of the American Ceramics Society, 53, 176-179.

Whittaker, E. J. W., Muntus, R. (1970). Ionic radii for use in geochemistry. Geochimica et Cosmochimica Acta, 9, 279-289.

Xue, X., Kanzaki M., Fukui, H. (2010). Unique crystal chemistry of two polymorphs of topaz-OH: A multi-nuclear NMR and Raman study. American Mineralogist, 95, 1276-1293. 